\title{
O Programa ClênCia 2007 no CQB - Das Moléculas aOS NANOMATERIAIS E À BIOMEDICINA
}

\author{
Pedro D. Vaz ${ }^{1}$, Carla D. Nunes ${ }^{1, *}$, Olinda C. Monteiro ${ }^{1}$, Ana \\ S. Viana ${ }^{1}$, Rodrigo F. M. de Almeida e Pedro Lima ${ }^{1}$
}

\begin{abstract}
0 Centro de Química e Bioquímica (CQB; http://cqb.fc.ul.pt) foi fundado em 2001 na Faculdade de Ciências da Universidade de Lisboa tendo, por isso, recentemente celebrado o seu décimo aniversário. Um dos aspetos mais importantes na génese do CQB foi o intuito de criar um ambiente de trabalho onde grupos de investigação com diferentes interesses em Química e Bioquímica pudessem estabelecer interações profícuas nas fronteiras dessas duas áreas. Tal filosotia tem estado sempre presente no Centro, e os doze grupos que atualmente constituem o CQB colaboram, frequentemente, na preparação e caracterização de moléculas e materiais com funcionalidades específicas em vista, e no estudo de regulação bioquímica, etiologia e terapêutica de doenças. Um bom espelho disso são os trabalhos descritos no presente artigo, da iniciativa dos seis investigadores que integraram o CQB na sequência do programa Ciência 2007, lançado pela Fundação para a Ciência e a Tecnologia.
\end{abstract}

ARGILAS COMO RESERVATÓRIO DE IÕES PARA MALDI-MS - PEDRO D. VAZ

Os hidróxidos duplos lamelares (HDL), também conhecidos como argilas aniónicas, de que a hidrotalcite (HT) é um bom exemplo, constituem uma importante classe de minerais naturais. A sua estrutura é formada por lamelas de óxidos metálicos mistos e apresentam um espaço interlamelar com aniões. Tais materiais têm a capacidade de intercalar aniões, tornando-se muito versáteis em termos de manipulação estrutural. A sua síntese laboratorial é bastante fácil e, além disso, apresentam não só uma química de intercalação rica, com a qual se pode jogar, mas, também, uma vasta gama de composições [1] Este último aspeto é refletido pela sua fórmula geral,

$$
\left[\mathrm{M}_{1-x}^{2+} \mathrm{M}_{x}^{3+}(\mathrm{OH})_{2}\right]\left[\mathrm{A}^{m-}\right]_{x / m} \cdot n \mathrm{H}_{2} \mathrm{O}
$$

onde $\mathrm{M}^{2+}$ e $\mathrm{M}^{3+}$ representam catiões metálicos como $\mathrm{Mg}^{2+}$ e $\mathrm{Al}^{3+}, \mathrm{A}^{m-}$ um anião simples como $\mathrm{Cl}^{-}, \mathrm{NO}_{3}^{-}$ou $\mathrm{CO}_{3}^{2-}$ e $x$ a quantidade relativa de $\mathrm{M}^{3+}$, correlacionando também com o espaçamento das lamelas [1]. O espaçamento interlamelar é dinâmico, dependendo do tamanho dos aniões intercalados (hóspedes; podem variar de aniões simples orgânicos ou inorgânicos até biomoléculas carregadas

Centro de Quimica e Bioquimica e Departamento de Quimica e Bioquimica, Faculdade de Ciências da Universidade de Lisboa, 1749-016 Lisboa cmnunes@fc.ul.pt negativamente) e do grau de hidratação. A intercalação de aniões pode ser efetuada por meio de reidratação de um precursor calcinado, por troca iónica direta ou, ainda, por síntese do HDL na presença do anião [1].

Estes materiais encontram aplicações em campos como a catálise, a fotoquímica, ou o ambiente (para captação de metais, compostos orgânicos voláteis ou poluentes orgânicos persistentes) [2]. Podem também ser utilizados em problemas de saúde humana, atuando, por exemplo, como reservatórios de aminoácidos/ péptidos. Em particular, a hidrotalcite, $\left[\mathrm{Mg}_{6} \mathrm{Al}_{2}\left(\mathrm{CO}_{3}\right)(\mathrm{OH})_{16}\right]$, é comercializada como antiácido sob o nome comercial Talcid $^{\circledast}$ pela Bayer Healthcare.

Uma outra aplicação importante dos hidróxidos duplos lamelares é a análise por espetrometria de massa com ionização por dessorção laser assistida por matriz (MALDI-MS) [3]. A espe- trometria de massa é uma técnica que tem vindo a evoluir aceleradamente, mediante o desenvolvimento de espectrómetros cada mais sensiveis e de novas técnicas de ionização. O MALDI-MS é um método suave e eficaz de ionização de compostos termolábeis e não voláteis, como biomoléculas (péptidos, proteínas, oligonucleótidos e oligossacáridos) ou polímeros. A sua principal desvantagem é o facto de as matrizes orgânicas tradicionalmente usadas (ácidos $\alpha$-cianocinâmino ou 2,5-dihidroxibenzóico) na ionização de amostras com baixo peso molecular (ex. aminoácidos) interferirem, frequentemente, na análise [4]. Verificou-se, porém, que nestes casos era possível solucionar o problema mediante intercalação dos compostos a analisar (ex. triptofano e fenilalanina) na hidrotalcite, usando-a posteriormente sem a adição de qualquer outra matriz na análise MALDI-MS (Figura 1). Isto foi demonstrado tirando partido das potencialidades de um espectrómetro

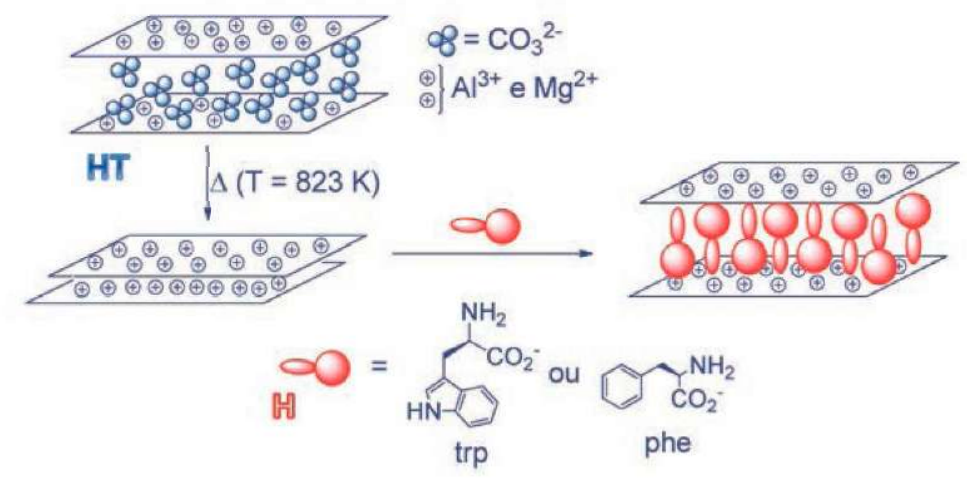

Figura 1 - Intercalação de hóspedes $(\mathrm{H})$ triptofano (trp) e fenilalanina (phe) no espaço interlamelar da hidrotalcite (HT) 
de massa de ressonância ciclotrónica de ião com transformada de Fourier (FT-ICR-MS), conforme ilustrado na Figura 2. Esta infraestrutura existente no CQB é única no país e possui uma fonte combinada de electrospray e MALDI. A espetrometria de massa com FT-ICR é presentemente a técnica que permite realizar estudos nesta área com as mais altas resolução e exatidão [5].

Além disso, durante as experiências de MALDI-MS, verificou-se não haver interferência do material hospedeiro, isto é, não são detetados iões pertencentes ao material hospedeiro, mostrando que a argila é estável sob tais condições, o que é uma vantagem sobre outros sistemas. Mesmo de um ponto de vista económico pode-se tirar vantagem do efeito de memória das argilas, visto que estas podem ser reutilizadas em vários ciclos da experiência de adsorção/análise, realizando um passo de calcinação pelo meio. O processo de ionização é provavelmente baseado num processo de transferência de energia em excesso a partir da argila para o analito, após irradiação com o laser que induz a ejeção dos iões para a fase gasosa [2]

A possibilidade de alterar a natureza do material hospedeiro $(\mathrm{HT})$ para conseguir reter novas moléculas no seu interior, combinada com a capacidade de os expulsar do espaço interlamelar, quando necessário, constitui uma aplicação de elevado interesse. De um ponto de vista analítico, será vantajoso, uma vez que tais materiais são conhecidos por conseguirem captar uma vasta gama de moléculas com pesos moleculares variados e com diferentes origens. Foi demonstrado que a hidrotalcite pode intercalar muitas espécies, mesmo em baixa concentração. Desta forma permitem o estudo de matrizes complexas, mostrando que estes materiais podem competir com outros métodos, tais como a barra de agitação de extração sortiva.

\section{MATERIAIS MESOPOROSOS PARA REME- DiaÇão ambiental - Carla D. Nunes}

O confinamento de complexos metálicos em materiais de várias naturezas é um conceito conhecido e utilizado na conceção de novos catalisadores heterogéneos. Os materiais zeolíticos apresentam algumas limitações para este efeito, por se tratarem de materiais microporosos, com um reduzido tamanho dos poros $\left(<12 \AA, 1 \AA=10^{-10} \mathrm{~m}\right)$, o que levou a uma investigação intensa, culminando no desenvolvimento de novas estruturas com poros mais largos (materiais mesoporosos). Os materiais porosos classificam-se em três tipos consoante o diâmetro dos
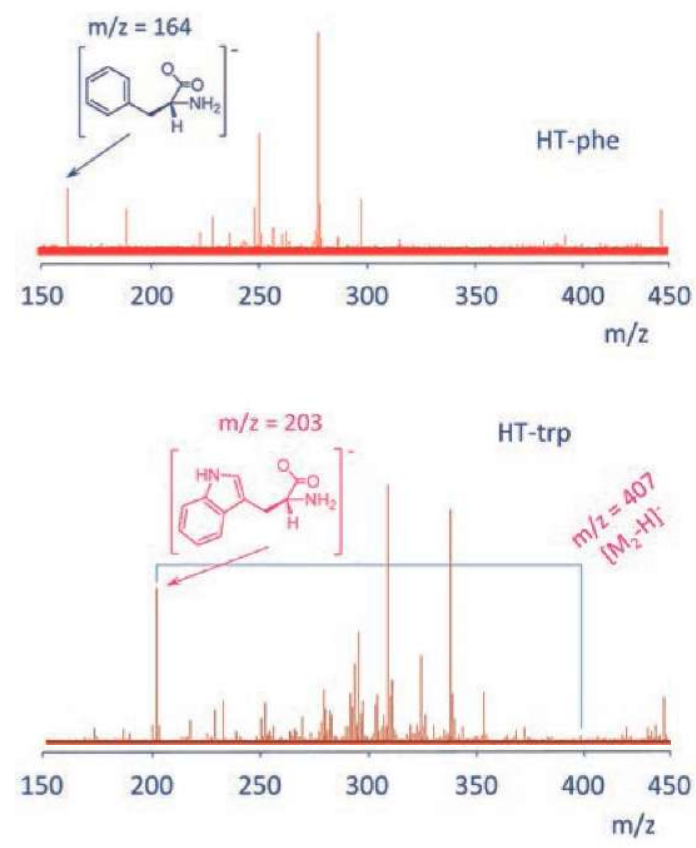

Figura 2 - Espetros de massa de alta resolução por MALDI-MS dos aminoácidos intercalados em HT

seus poros, canais ou cavidades. Assim, entre $3 \AA$ e $20 \AA$ os materiais designam-se por microporosos (ex. zeólitos), entre $20 \AA$ e $500 \AA$ A por mesoporosos e, acima desta gama, por macroporosos.

Avanços significativos nos materiais mesoporosos verificaram-se a partir de 1991, com o aparecimento da família M41S desenvolvida pela Mobil Oil Company [6]. Estes materiais possuem poros com tamanhos bem definidos e um diâmetro uniforme (geralmente entre $15 \AA$ a $100 \AA$ ), assim como elevadas áreas superficiais $\left(>1000 \mathrm{~m}^{2} \cdot \mathrm{g}^{-1}\right)$. O diâmetro dos poros é passivel de ser ajustado através da utilização de agentes tensioativos com cadeias carbonadas de tamanho variável e compostos orgânicos incrementadores, como, por exemplo, o 1,3,5-trimetilbenzeno [6, 7]. A família M41S é constituída por três mesoestruturas ordenadas e bem definidas com arranjo de poros hexagonal (MCM-41), cúbico (MCM-48) ou lamelar (MCM-50), sendo todas elas sintetizadas em meio alcalino. O sistema com o arranjo hexagonal, conhecido como MCM-41, é o membro mais importante e mais exaustivamente estudado da família M41S. Foi descrito pela primeira vez por Kresge e colaboradores $[6,7]$ e, ao contrário de outros materiais mesoporosos que, geralmente, possuem poros com espaçamentos irregulares, o MCM-41 apresenta canais unidirecionais que se organizam hexagonalmente no espaço como uma colmeia e com uma estreita distribuição do diâmetro dos poros. Entre outras aplicações, os materiais mesoporosos são bons candidatos a suportes de catalisadores, devido ao elevado e uniforme diâmetro dos poros, podendo assim ser usados como hospedeiros para a incorporação de diferentes metais, criando e alargando a atividade no interior das estruturas porosas [8].

Os catalisadores heterogéneos têm provado ser bons candidatos para substituírem os homogéneos. A sua seletividade tem melhorado e a fácil recuperação do meio reacional facilita o seu uso em ciclos consecutivos. Assim têm sido uma prioridade e um desafio para quem trabalha nesta área [8]. 
A utilização destes materiais tem sido igualmente direcionada para processos de remediação ambiental, associada a novos processos de oxidação. No caso particular da indústria têxtil, os corantes são uma perigosa fonte de contaminação ambiental, devido à sua resistência à biodegradação. Vários processos como sonicação, fotocatálise e reações de Fenton têm surgido como opções para a decomposição de compostos orgânicos em meio ácido ou neutro [9]

Tendo como ponto de partida estas ideias, realizou-se um estudo sobre a fotodegradação da Rodamina B (corante modelo) usando $\mathrm{MCM}-41$ derivatizado com complexos de molibdénio, nomeadamente $\left[\mathrm{MO}^{\prime \prime} \mathrm{I}_{2}(\mathrm{CO})_{3} \mathrm{~L}\right] \mathrm{e}$ $\left[\mathrm{MoV}^{\mathrm{V}} \mathrm{O}_{2} \mathrm{Cl}_{2} \mathrm{~L}\right]$ em que:

$\mathrm{L}=\mathrm{O}-\mathrm{C}_{5} \mathrm{H}_{5} \mathrm{~N}-\mathrm{NH}-\mathrm{CH}_{2}-\mathrm{CH}(\mathrm{OH})-\left(\mathrm{CH}_{2}\right)_{3}-\mathrm{Si}\left(\mathrm{OCH}_{3}\right)_{3}$

Estes complexos atuam como catalisadores em reações fotocatalíticas de transferência de oxigénio. Os materiais sintetizados tiram vantagem, quer da elevada área superficial do hospe- deiro, quer das propriedades fotocatalíticas dos complexos (Figura 3) [9].

Para identificar e quantificar os produtos obtidos após a fotodegradação, realizaram-se estudos de espetrometria de massa com ionização por electrospray. Obtiveram-se como produtos a anilina, no caso de ser usado o material com Mo", ou anilina, hidroxianilina, ácido benzóico, ácido hidroxibenzóico e dihidropirano, usando o material com Movl. Muito provavelmente obteve-se também $\mathrm{H}_{2} \mathrm{O}$ e $\mathrm{CO}_{2}$, mas não são detetáveis por espetrometria de massa. O próprio MCM-41 apresenta alguma atividade fotocatalítica, tendo sido obtido o xanteno como produto maioritário. Como vantagem do processo catalítico é de referir que os testes foram realizados em condições aeróbicas, ou seja, sob atmosfera normal e sem adição de qualquer outro oxidante $\left(\mathrm{O}_{2}\right.$ ou $\left.\mathrm{H}_{2} \mathrm{O}_{2}\right)$ resultando assim num processo mais limpo e barato que outros processos publicados (Figura 4).

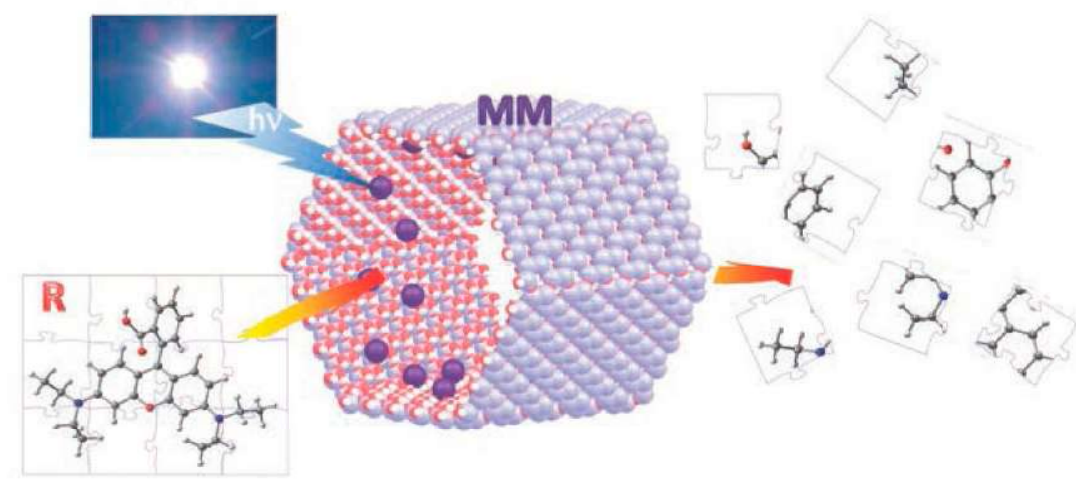

Figura 3 - Fotodegradação catalítica da Rodamina B (R) com materiais mesoporosos (MM)

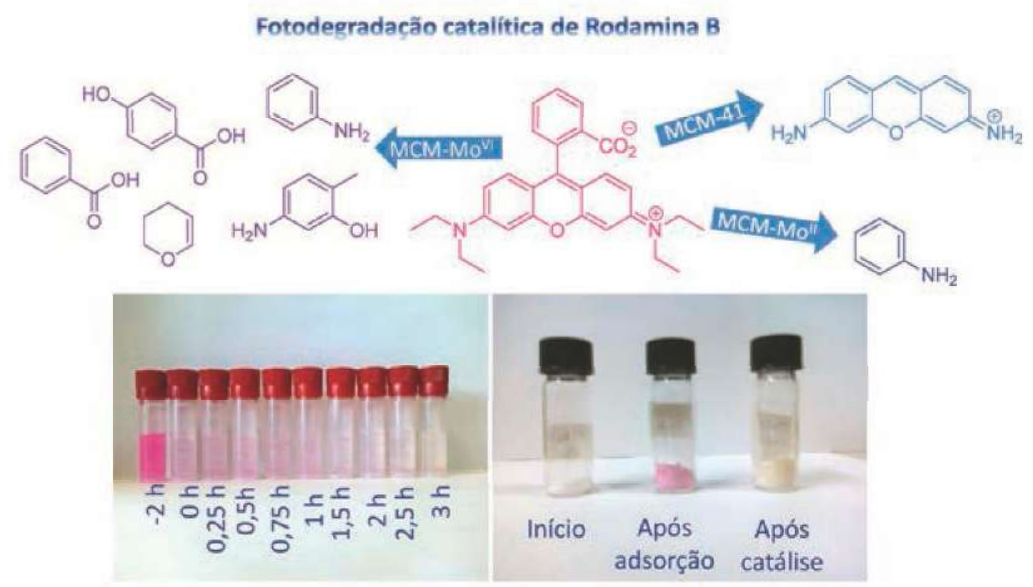

Figura 4 - Produtos resultantes da fotodegradação da Rodamina B e evolução temporal da degradação do corante em solução e no catalisador

\section{A ARTE DE COLORIR NANOTUBOS - Olinda C. Monteiro}

Um dos maiores desafios da atualidade, na área do desenvolvimento nanotecnológico, é conseguir, por manipulação a uma escala atómica/ molecular, um controle preciso das propriedades intrínsecas dos materiais. A síntese de materiais compósitos/híbridos tem sido um dos métodos mais usados para atingir esse objetivo. Desta forma, e como resultado de uma combinação sinergética de dois ou mais componentes, torna-se possível a criação de novos materiais com propriedades inovadoras ou melhoradas. Este trabalho insere-se nesta temática e tem como principal objetivo o fabrico de novos materiais nanoestruturados com propriedades modificadas.

O interesse nas nanoestruturas de titanatos foi despoletado em 1998 pelo trabalho de Kasuga et al. [10]. Os nanotubos de titanatos (TNTs) são capazes de combinar as propriedades e aplicações das nanopartículas de $\mathrm{TiO}_{2}$ (por exemplo, atividade fotocatalítica) com as propriedades dos titanatos lamelares (por exemplo, capacidade de troca iónica). A sua limitada aplicabilidade como materiais foto-ativos na região do visível deve-se à fraca absorção de energia e à elevada capacidade de recombinação eletrónica. A combinação com um segundo elemento pode permitir ultrapassar estas limitações, por alargamento da banda de absorção e/ou por diminuição da recombinação. Através do recurso a vários processos de fotossensibilização pretende-se derivatizar TNTs de forma a melhorar o seu desempenho ótico na região de radiação visível. Uma criteriosa seleção do(s) sensibilizador(es) a usar permite manipular as propriedades estruturais, eletrónicas, óticas e magnéticas do material compósito.

\section{Efeito do solvente}

Um dos problemas subjacentes à preparação hidrotérmica de TNTs relaciona-se com o facto de as propriedades do material obtido serem fortemente dependentes da natureza do $\mathrm{TiO}_{2}$ usado, o que nos levou recentemente a propor um procedimento de 
síntese alternativo [11]. A substituição do solvente $\mathrm{H}_{2} \mathrm{O}$ por uma solução de $\mathrm{NaOH} 10 \mathrm{M}$ resulta na formação de estruturas alongadas em detrimento de nanopartículas esféricas de $\mathrm{TiO}_{2}$ anatase (Figura 5).

\section{Troca iónica $\mathrm{Na}^{+} \rightarrow \mathrm{H}^{+}$}

As alterações introduzidas nos TNTs $\left(\mathrm{Na}_{2-x} \mathrm{H}_{x} \mathrm{Ti}_{3} \mathrm{O}_{7} \cdot n \mathrm{H}_{2} \mathrm{O}\right.$, com $\left.0 \leq x \leq 2\right)$ pelo simples processo de troca iónica $\mathrm{Na}^{+} \rightarrow \mathrm{H}^{+}$revelaram-se bastante interessantes ao estudar as propriedades óticas, de adsorção e foto-catalíticas, destes materiais: a extensão da adsorção de corantes catiónicos é fortemente condicionada pelo grau de substituição de $\mathrm{Na}^{+}$; a banda de absorção sofre desvios para a região do visível com a diminuição da quantidade de sódio na estrutura; quer o desempenho foto-catalítico quer o mecanismo de degradação de poluentes industriais são condicionados pela composição química dos TNTs [12].

\section{Dopagem com cobalto}

Ao contrário do que se passa com - $\mathrm{TiO}_{2}$ [13], a estrutura, dimensões e morfologia das partículas de TNTs sofrem fortes alterações quando dopadas com cobalto. A introdução do metal na rede cristalina permite ajus-

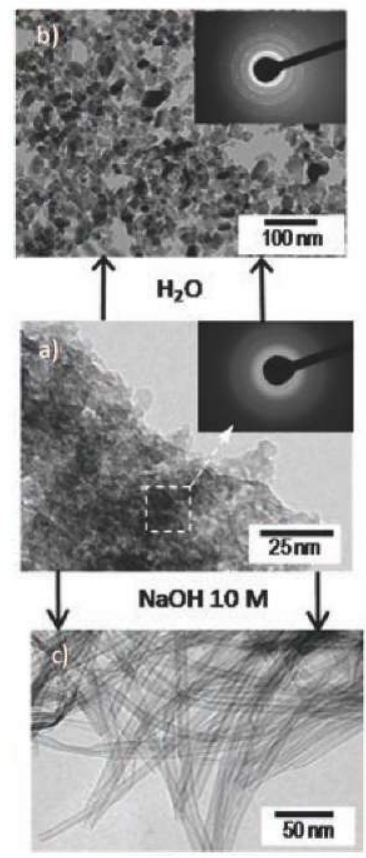

Figura 5 - Imagens de microscopia eletrónica de transmissão (TEM) das partículas do precursor (a) do $\mathrm{TiO}_{2}$ (b) e de TNTs (c) preparados por tratamento hidrotérmico tar o nível de energia das bandas de condução e valência e, consequentemente, reduzir a recombinação eletrónica. Observa-se ainda um desvio para o visível da banda de absorção do material.

\section{Fotossensibilização com semicon- dutores nanocristalinos/corantes orgânicos}

O fabrico de TNTs modificados por fotossensibilização, usando semicondutores nanocristalinos ou corantes orgânicos, permite a expansão do limite de absorção destes materiais até à zona do infravermelho próximo (NIR), dependendo do sensibilizador.

Como exemplo, a decoração dos TNTs com CdS conduz à formação de um nanocompósito (Figura 6). O desvio no valor da energia da banda de absorção é atribuído à presença de CdS apresentando efeitos de confinamento quântico [14]. Presentemente, estes materiais estão a ser estudados para aplicações de base solar (por exemplo foto-catálise e células solares).

\section{FuncionalizaÇÃO DE SUPERFÍCIES} PARA BIOSSENSORES - ANA S. VIANA

O desenvolvimento de biossensores eletroquímicos e óticos para aplica-

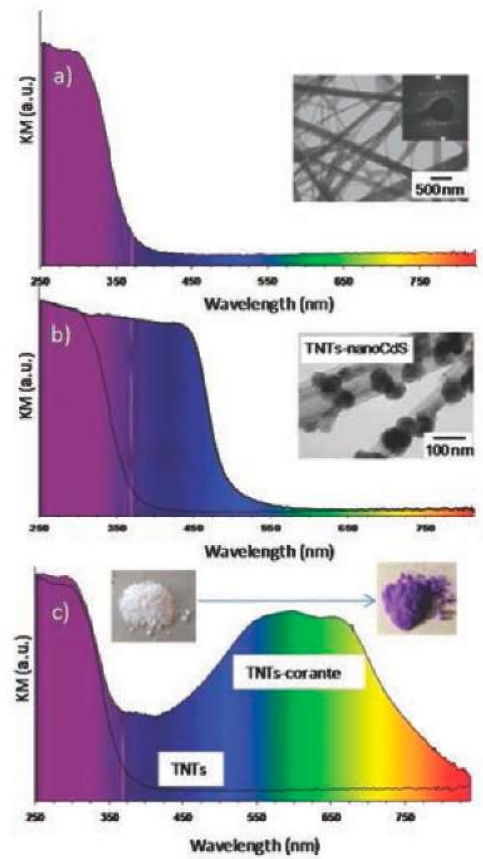

Figura 6 - Espectros óticos de TNTs antes (a) e após sensibilização com CdS nanocristalino (b) e com corante orgânico (c) ção em análises clínicas tem sido alvo de investigação intensa e inovadora. Um dos biossensores mais rentáveis no mercado é o biossensor enzimático, utilizado diariamente por diabéticos, que deteta glicose no sangue por métodos eletroquímicos [15]. Para estender 0 uso destes dispositivos a matrizes ainda mais complexas, nomeadamente no âmbito do ramo alimentar, existem diversos desafios tecnológicos para melhorar limites de deteção (incluindo inibição da adsorção não específica), estabilidade e miniaturização dos biossensores. Um dos passos determinantes na construção de biossensores é a imobilização adequada de biomoléculas em superfícies, para que a orientação ou possíveis alterações de conformação não comprometam a sua atividade biológica.

No nosso laboratório estamos a estudar um método alternativo de imobilização covalente de biomoléculas em superfícies de ouro, com o objetivo de reduzir consideravelmente o número de passos envolvidos em processos mais convencionais. Estes últimos utilizam, por exemplo, monocamadas auto-montadas de tióis com grupos terminais $\left(-\mathrm{NH}_{2}\right.$ ou $\left.-\mathrm{COOH}\right)$ suscetíveis de serem ativados para a formação de ligações peptídicas com proteínas [16]. A nova metodologia baseia-se na formação in situ de ditiocarbamatos, por reação, num só passo, entre dissulfureto de carbono e grupos amina presentes nos aminoácidos das proteínas e na sua adsorção forte ao ouro. O método foi validado para compostos eletroativos contendo aminas primárias (dopamina) e secundárias (adrenalina) e ainda um aminoácido (triptofano) [17], quer em meio orgânico, quer em meio aquoso. Ao efetuar a reação na presença de nanopartículas de Au e Pt (com diâmetros $\leq 20 \mathrm{~nm}$ ) é possivel aumentar significativamente a quantidade de compostos alvo, devido à elevada área superficial das nanopartículas.

A Figura $7($ a) ilustra o método utilizado na preparação de um imunossensor anticorpo (imunoglobulina G, lgG) / antigénio (anti-imunoglobulina G, Anti-lgG), que poderá ser adaptado a outros anticorpos de interesse. A proteína $A$ interage especificamente 
com uma zona da $\lg G$, deixando disponível a região do anticorpo que faz o reconhecimento biológico do antigénio. Durante a conceção de estruturas organizadas a nível molecular, é essencial recorrer a técnicas de caracterização complementares que permitam obter uma visão global da interface em cada etapa da modificação. A Figura 7(b) mostra uma imagem da superfície de ouro modificada com proteína $\mathrm{A} \mathrm{e} \mathrm{CS}_{2}$ após incubação com $\lg$, captada por microscopia de força atómica (AFM). Distinguem-se, claramente, inúmeras proteínas individuais (estruturas globulares com 15-20 nm de diâmetro; círculos exemplificam moléculas individuais) com o espaçamento necessário para uma interação eficaz com o antigénio. Tal como o ditiocarbamato formado por reação entre o $\mathrm{CS}_{2}$ e a proteína $A$, também as moléculas de $\mathrm{CS}_{2}$ que não reagiram podem adsorver na superfície (Figura $7(a))$. Uma vez que o carbono do $\mathrm{CS}_{2}$ perde reatividade para os grupos amina após estabelecer uma ligação forte ao ouro, estas moléculas têm um papel crucial na inibição da adsorção física (não específica) das proteínas. A voltametria cíclica (desadsorção redutiva) permite confirmar a presença da ligação Au-S e estimar o número de átomos de $S$ adsorvidos [16]. Utiliza-se também para comprovar a modificação da superfície, incluindo o reconhecimento IgG/Anti-lgG, através do aumento do bloqueio (Figura 7(c)) ao processo redox de uma espécie, $\left[\mathrm{K}_{3} \mathrm{Fe}(\mathrm{CN})_{6}\right]$, em solução (decréscimo das correntes de oxidação e redução). A Ressonância de Plasmão de Superfície (SPR) é uma técnica muito sensível para detetar em tempo real as variações no índice de refração da interface. A Figura $7(d)$ revela uma variação nítida da intensidade do sinal ótico quando existe afinidade biológica estável entre Proteína A/lgG e IgG/Anti-lgG. A lavagem com solução tampão remove as moléculas que interagem fracamente com a superfície modificada. Os resultados são corroborados por Elipsometria, que permite estimar a espessura das diversas camadas/subcamadas e avaliar a capacidade de inibição da adsorção não específica.

A simplicidade do método, a possibilidade de ser efetuado em meio aquo- so e tamponado e a capacidade para prevenir a adsorção de outras proteínas evidenciam o seu potencial na construção de biossensores.

Combater fungos PATOGÉnicos: A LEVEDURA "COMUM" COMO MODELO Rodrigo F. M. DE ALMEIDA

A frequência de infeções mortais por fungos aumentou dramaticamente nos últimos tempos, em particular entre os doentes com vírus da imunodeficiência humana (HIV) e pacientes com cancro que recebem quimioterapia imunossupressora.

As principais terapias antifúngicas atualmente em uso clínico atuam a nível da membrana plasmática dos fungos, tendo em conta as reconhecidas diferenças entre a membrana desses organismos e das células humanas. Um dos exemplos mais marcantes é a ausência de colesterol, cujo papel é desempenhado nos fungos por uma molécula análoga, o ergosterol (Figuras $8(a)$ e $8(b))$. Apesar das diferenças estruturais entre estas duas moléculas serem subtis, a sua presença nas membranas confere-lhes propriedades biofísicas marcadamente distintas. Quando a membrana celular é o alvo terapêutico, não basta apenas considerar cada molécula individualmente, uma vez que as moléculas se difundem lateralmente a velocidades elevadas (coeficientes de difusão lateral que podem ser da ordem de $10^{-8} \mathrm{~cm}^{2} \cdot \mathrm{s}^{-1}$ ) e estabelecem inúmeras interações que resultam numa organização altamente hierarquizada com regiões de diferentes composições e propriedades biofísicas, como espessura, fluidez e permeabilidade. Ao contrário da maioria dos fármacos, que atuam especificamente numa molécula alvo, normalmente uma proteína, o mecanismo de ação dos fármacos dirigidos às biomembranas pode passar pelas alterações provocadas na sua organização e propriedades biofísicas, não sendo possível assim identificar um alvo molecular único. Importa, pois, estudar essas propriedades, quer no organismo que provoca a infeção, quer em células animais, para fazer uso dessas diferenças no desenvolvimento de terapias eficazes e de baixa toxicidade para os humanos.

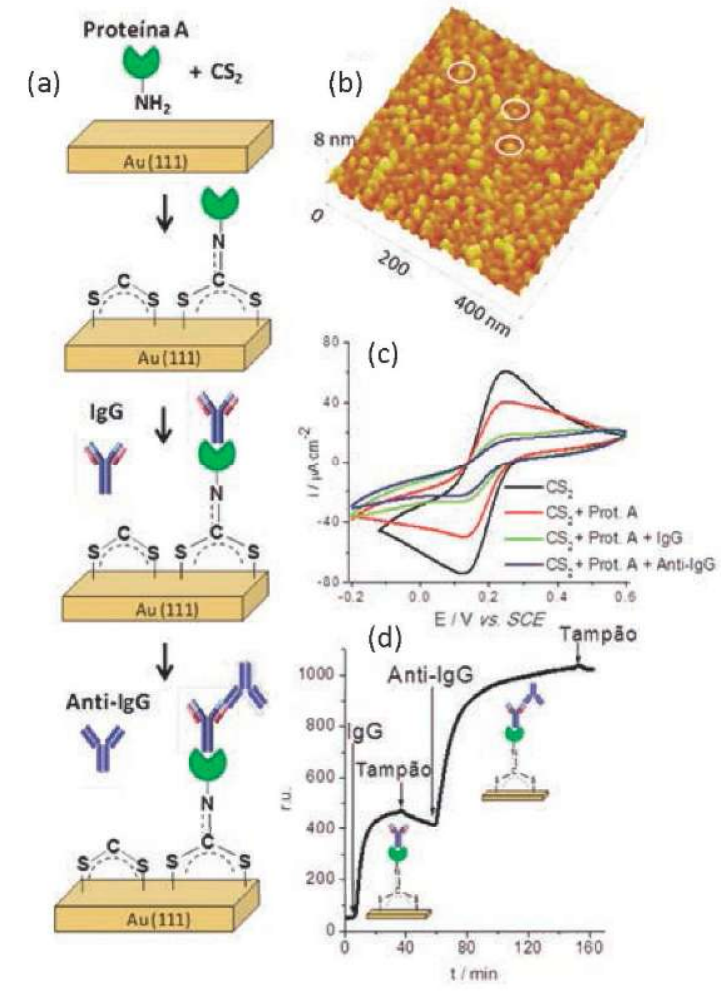

Figura 7 - (a) Esquema ilustrativo do imunossensor anticorpo/antigénio; (b) imagem de AFM (500 $\times 500 \mathrm{~nm}^{2}$ ), obtida em modo Tapping ${ }^{\mathrm{TM}}$ de ouro modificado com $\mathrm{CS}_{2}$ + Proteína A após incubação com IgG (circulos exemplificam moléculas individuais); (c) voltamogramas cíclicos de $1 \mathrm{mM}$ de $\mathrm{K}_{3} \mathrm{Fe}(\mathrm{CN})_{6}$ em tampão fosfato $(\mathrm{pH} 7)$ após várias etapas de modificação; e (d) Ensaio de SPR em tempo-real representando as reações de reconhecimento biológico $\mathrm{CS}_{2}+$ Proteína A/IgG e IgG / Anti-IgG 
Felizmente podemos estudar essas propriedades em laboratório num organismo não patogénico, a levedura do fermento de padeiro Saccharomyces cerevisiae, uma vez que a composição lipídica da sua membrana plasmática é idêntica à de vários fungos patogénicos. Muitas das ferramentas utilizadas para investigar as membranas de células de mamífero não foram aplicadas à membrana plasmática da levedura, mas é a aplicação dessas mesmas técnicas que permitirá pôr em evidência as diferenças entre elas [18]. Parte do trabalho que temos desenvolvido tem sido, pois, a caracterização das propriedades fotofísicas de sondas de membrana fluorescentes em membranas de células de levedura e em lipossomas que mimetizam as membranas destes organismos e que até hoje têm sido utilizadas quase exclusivamente em células de mamífero.

A membrana da levedura encontra-se compartimentada em regiões identificadas com marcadores proteicos que são facilmente observáveis por microscopia de fluorescência e que são estáveis no espaço e no tempo [19]. Pelo contrário, nas membranas de mamífero, a não ser que haja barreiras físicas bem definidas, os domínios formados são transientes e de dimensões inferiores à resolução das microscopias óticas convencionais.

Agora sabemos também que existem diferenças fundamentais a nivel da organização lipídica. No nosso laboratório descobrimos que a membrana plasmática da levedura contém domínios do tipo gel [20], isto é, regiões da membrana muito rígidas e ordenadas, com grande conteúdo em esfingolípidos e sem esteróis. Esta descoberta contraria o paradigma atual que preconiza a formação de domínios lipídicos com base nas interações esterol-esfingolípido (Figuras 8(c) e 8(d)). Entretanto, já observámos que esse tipo de domínio está presente noutras espécies de fungos (resultados não publicados). (a)

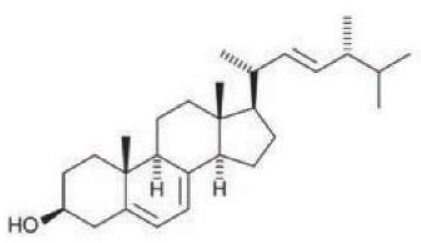

(c)
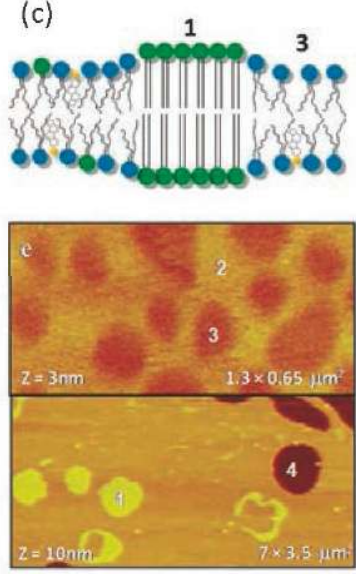

(b)

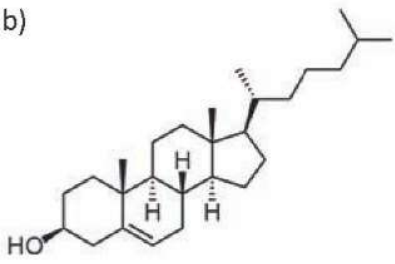

(d)
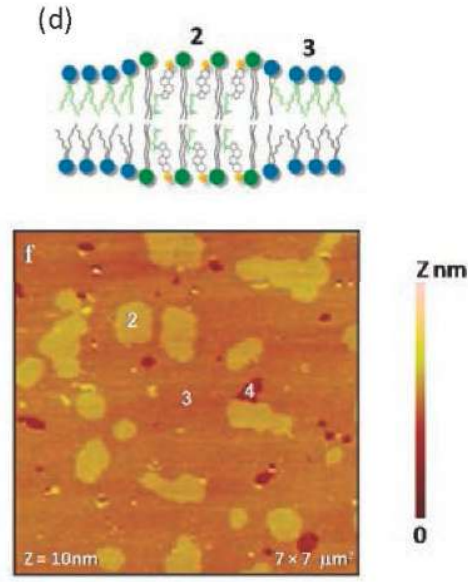

Figura 8 - Comparação entre a composição e a organização da membrana plasmática em fungos (levedura) versus mamíferos. $(a, b)$ estrutura do esterol predominante nos dois grupos de organismo, (a) ergosterol, (b) colesterol; (c, d) diagrama esquemático de uma membrana com (1) domínios de gel (rico em esfingolípidos) ou (2) domínios de líquido ordenado (rico em esterol e esfingolípidos) entre (3) regiões de líquido desordenado (rico em fosfolípidos insaturados). $(e, f)$ imagem de AFM obtida em modo Tapping ${ }^{\mathrm{TM}}$ em líquido de bicamadas lipídicas suportadas em mica constituídas por uma mistura ternária que mimetiza os domínios lipídicos de levedura

(e) versus mamífero (f). As bicamadas são compostas por dioleoilfosfatidilcolina (fosfolípido insaturado)/palmitoil-esfingomielina (esfingolípido de mamífero)/colesterol versus palmitoiloleoilfosfatidilcolina (fosfolípido insaturado)/fitoceramida (esfingolípido de levedura)/ergosterol, numa proporção molar de 2:2:1 em ambos os casos. Os diferentes tipos de domínios $(1,2,3)$ são identificados por diferenças de espessura da bicamada (Z). (4) corresponde a zonas de substrato (mica) descoberto

Presentemente, continuamos a caracterizar as propriedades biofísicas da membrana plasmática da levedura, quer in vivo, quer in vitro [21], usando diferentes abordagens experimentais, que vão desde a espectroscopia e microscopia de fluorescência, até à microscopia de força atómica (Figuras $8(e)$ e $8(f)$ ), para melhor perceber as semelhanças e diferenças relativamente às membranas das nossas células e contribuir para o desenvolvimento de novas terapias antifúngicas.

EXTRATO DE ESPONJA MARINHA PORTUGUESA COM POTENCIAL NO TRATAMENTO DA DOR - PEDRO LIMA

Os avanços em Neurociências e noutras áreas da Biomedicina, como a Cardiologia, ocorrem frequentemente em estreita associação com a descoberta de determinados agentes químicos que nos elucidam sobre 0 funcionamento dos neurónios e das células musculares. Estes agentes farmacológicos atuam especificamente em proteínas da membrana celular, nomeadamente nos canais iónicos. A função de cada canal iónico tem sido estabelecida recorrendo a esses agentes químicos, que nalguns casos são também usados para fins terapêuticos. Por exemplo, o potencial de ação nos neurónios é levado a cabo pela atividade concertada de múltiplos canais iónicos que conduzem seletivamente $\mathrm{Na}^{+}, \mathrm{K}^{+}$e $\mathrm{Ca}^{2+}$. Existe uma grande diversidade de subtipos de canais, cada um com o seu papel fisiológico específico - só canais de $\mathrm{K}^{+}$ existem mais de 50 [22]. A utilização de neurofármacos específicos, muitos dos quais provenientes de organismos marinhos, tem sido essencial para avaliar a função de cada um desses subtipos de canais. Existe assim um grande interesse na identificação de novos compostos com atividade em canais para os quais tais fármacos ainda não estão disponíveis.

A combinação de varias técnicas de eletrofisiologia (como o patch-clamp), e de imagiologia em tempo real (por exemplo, imagiologia de $\mathrm{Ca}^{2+}$ neural) permite-nos identificar e caracterizar um eventual efeito farmacológico numa determinada corrente iónica ou um processo celular que pode ser estudado numa célula isolada ou em 
tecidos ex vivo, nomeadamente em fatias de cérebro de ratos.

O caso aqui apresentado referente a um composto extraído de uma esponja marinha capturada em águas portuguesas constitui um exemplo desta abordagem (colaboração com Doutora Helena Gaspar, Grupo de Química Inorgânica e Teórica, CQB). Os nossos resultados revelaram que esse composto bloqueia correntes rápidas de $\mathrm{K}^{+}$ativadas por voltagem em neurónios isolados do hipocampo (Figuras $9(a)$ e $9(b))$. A uma concentração de $0,001 \%$ (peso/volume), o efeito é específico para a componente rápida dessa corrente com um tempo do decaimento $\tau \sim$ dezenas de milissegundos, não alterando a componente lenta para a qual $\tau \sim$ centenas de milissegundos (Figura 9(a)). Usando um protocolo de voltagem que visa isolar a componente rápida (inset da Figura 9(b)), é possível investigar o efeito mais detalhadamente [23]. A corrente sensível ao composto, obtida a partir da subtração da corrente controlo à registada aquando do tratamento, mostra um tempo de decaimento de 40 a $70 \mathrm{~ms}$. Foram efetuados outros registos para se estudar a sensibilidade da ativação da corrente à voltagem [24], um parâmetro identificador da corrente em foco. Globalmente, estes estudos permitem caracterizar a corrente de $\mathrm{K}^{+}$sensível ao composto que, neste caso, evidenciou uma cinética de inativação e um perfil de voltagem típicos dos canais do subtipo KV1.4. Este subtipo é considerado de elevada relevância no contexto da dor e até aqui não se conhecia qualquer agente químico que modulasse a sua atividade. De facto, o KV1.4 é o único canal $\mathrm{KV}$ de $\mathrm{K}^{+}$presente nos pain sensing neurons situados no gânglio dorsal da raiz $[22,25]$.

Consequentemente, uma vez que o composto isolado a partir da esponja portuguesa apresenta elevado potencial no tratamento da dor crónica, pretendeu-se investigar um eventual efeito também no canal de $\mathrm{K}^{+}$'cardíaco' human ERG (hERG). Este ensaio constitui um importante teste pré-clíni$c o$, uma vez que o canal hERG é preponderante no controlo do batimento cardíaco, sendo desejável que não haja efeitos nesse canal. Observou- -se que o composto, mesmo em concentrações mais elevadas $(0,01 \%)$ não alterou as correntes registadas a partir de células HEK (Human Embronic Kidney) que expressam apenas o canal hERG (Figura 9(c)). Em conclusão, estamos perante um potencial neurofármaco que, ao atuar especificamente no canal KV1.4, poderá ser usado no tratamento da dor crónica sem alterar a atividade cardíaca mediada pelos canais de $\mathrm{K}^{+}$cardíacos.

\section{Agradecimentos}

Os autores agradecem a todos aqueles que estiveram envolvidos nestes trabalhos, à $\mathrm{FCT}$, pelos projetos:

PTDC/QUI/66612/2006,

POCI/QUI/71576/2006,

PTDC/CTM-NAN/113021/2009,

PTDC/QUI-BIQ/104311/2008

e PTDC/CTM/101033/2008

PEst-OE/QUI/UI0612/2011,

Pessoa-Egide Proc. 441.00 (20102011); ASSEMBLE 2047/G6/EU FP7 (2010-2012), Cooperação Transnacional Portugal/R.P. China (FCT/ MOST) 2010-2012.

Um agradecimento especial à Maria José Calhorda pela revisão e comentários oportunos e ao Manuel Minas da Piedade, coordenador do Centro de Química e Bioquímica pela nota introdutória, revisão e comentários igualmente construtivos.

\section{REFERÊNCIAS}

[1] S.P. Newman, W. Jones, New J. Chem. 22 (1998) 105-115.

[2] P.D. Vaz, C.D. Nunes, New J. Chem. 34 (2010) 541-546 (a)

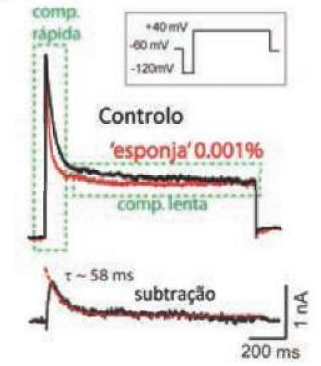

(b)

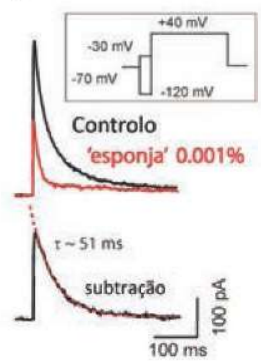

[3] M. Karas, F. Hillenkamp, Anal. Chem. 60 (1988) 2299-2301.

[4] G. Zhong, H. Lin, Anal. Bioanal. Chem. 387 (2007) 1939-1944.

[5] P.J.A. Amorim Madeira, P.A. Alves, C.M. Borges, 'High Resolution Mass Spectrometry Using FTICR and Orbitrap Instruments', in: S.M. Salih (ed.), Fourier Transform - Materials Analysis, Croatia: Intech (2012) 25-44.

[6] C.T. Kresge, M.E. Leonowicz, W.J. Roth, J.C. Vartuli, J.S. Beck, Nature 359 (1992) 710-712.

[7] J.S. Beck, J.C. Vartuli, W.J. Roth, M.E. Leonowicz, C.T. Kresge, K.D. Schmitt, C.T.W. Chu, D.H. Olson, E.W. Sheppard, S.B. McCullen, J.B. Higgins, J.L. Schlenker, J. Am. Chem. Soc. 114 (1992) 10834-10843.

[8] N.U. Silva, C.I. Fernandes, T.G. Nunes, M.S. Saraiva, C.D. Nunes, P.D. Vaz, Appl. Catal. A-Gen. 408 (2011) 105-116.

[9] N.U. Silva, T.G. Nunes, M.S. Saraiva, M.S. Shalamzari, P.D. Vaz, O.C. Monteiro, C.D. Nunes, Appl. Catal. B-Environ. 113 (2012) 180-191.

[10] T. Kasuga, M. Hiramatsu, A. Hoson, T. Sekino, K. Niihara, Langmuir 14 (1998) 3160-3163.

[11] E. YIhäinen, M. Nunes, A. Silvestre, O. Monteiro, J. Mater. Sci. 47 (2012) 4305-4312.

[12] V. Bem, M.C. Neves, M.R. Nunes, A.J. Silvestre, O.C. Monteiro, J. Photochem. Photobiol. A: Chem. 232 (2012) 50-56.

[13] M.R. Nunes, O.C. Monteiro, A.L. Castro, D.A. Vasconcelos, A.J. Silvestre, Eur. J. Inorg. Chem. 2008 (2008) 961965.

[14] O.C. Monteiro, A.C.C. Esteves, T. Trindade, Chem. Mater. 14 (2002) 2900-2904

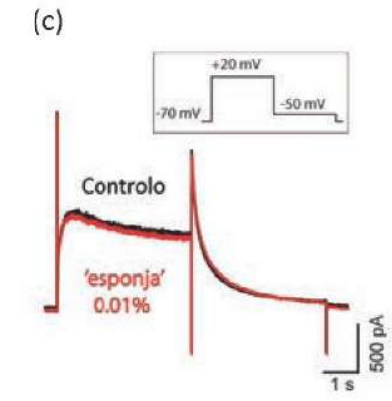

Figura 9 - Registos de whole cell voltage clamp a partir de $(\mathrm{a}, \mathrm{b})$ neurónios piramidais isolados da região do hipocampo de ratos Wistar e de (c) células HEK transfectadas com o canal 'car díaco' hERG (human ERG). As correntes foram obtidas antes (preto-controlo) e durante o tratamento com o composto de esponja (vermelho). Os protocolos de voltagem usados para evocar as correntes são esquematizados no inset em cada painel. Curvas descontínuas a vermelho representam o ajuste de funções exponenciais cujos tempos de decaimento $(\tau)$ são mostrados 
[15] J. Wang, Chem. Rev. 108 (2007) 814 825.

[16] Z.-H. Wang, A.S. Viana, G. Jin, L.M. Abrantes, Bioelectrochemistry 69 (2006) 180-186.

[17] I. Almeida, A.C. Cascalheira, A.S. Viana, Electrochim. Acta 55 (2010) 8686-8695.

[18] A.E.P. Bastos, H.S. Marinho, A.M. Cordeiro, A.M. de Soure, R.F.M. de Almeida, Chem. Phys. Lipids 165 (2012) 577-588.

[19] J. Malinsky, M. Opekarová, W. Tanner, Yeast 27 (2010) 473-478.
[20] F. Aresta-Branco, A.M. Cordeiro, H.S Marinho, L. Cyrne, F. Antunes, R.F.M. de Almeida, J. Biol. Chem. 286 (2012) 5043-5054.

[21] A.E.P. Bastos, S. Scolari, M. Stöckl, R.F.M. de Almeida, 'Chapter Three Applications of Fluorescence Lifetime Spectroscopy and Imaging to Lipid Domains In Vivo', in: E. Jankowsky (ed.), Methods in Enzymology - Imaging and Spectroscopic Analysis of Living Cells. Optical and Spectroscopic Techniques (v. 504), New York: Academic Press (2012) 57-81.
[22] W.A. Coetzee, Y. Amarillo, J. Chiu, A Chow, D. Lau, T. McCormack, H. Moreno, M.S. Nadal, A. Ozaita, D. Pountney, M. Saganich, E. Vega-Saenz de Miera, B. Rudy, Ann N Y Acad Sci 868 (1999) 233-285.

[23] M.I. Vicente, P.F. Costa, P.A. Lima, Eur J Pharmacol 634 (2010) 16-25.

[24] P.A. Lima, M.I. Vicente, F.M. Alves, J.C. Dionisio, P.F. Costa, Eur J Neurosci 27 (2008) 2019-2032.

[25] M.N. Rasband, E.W. Park, T.W. Vanderah, J. Lai, F. Porreca, J.S. Trimmer, Proc Natl Acad Sci U S A 98 (2001) 13373-13378.

\section{Atualidade Cientifica}

\section{NOVA TÉCNICA PARA A SIMULAÇÃO DE MATERIAIS NÃO CRISTALINOS}

Uma equipa multidisciplinar de investigadores do MIT, em colaboração com um investigador espanhol, descobriu uma abordagem matemática inovadora para a simulação do comportamento eletrónico de materiais não cristalinos, que poderão conduzir ao desenvolvimento de novos dispositivos como células fotovoltaicas, LED's orgânicos e circuitos eletrónicos flexíveis.

O novo procedimento matemático proporciona previsões com elevada exatidão. Deste modo, a pesquisa liderada por Jiahao Chen, pós-doc no Departamento de Química do MIT, foi reportada no fascículo da Physical Review Letters, publicado no dia 29 de junho.

O trabalho usou um conceito matemático designado por probabilidade livre aplicada a matrizes aleatórias, até agora considerado uma abstração sem aplicações práticas conhecidas. A equipa considerou este conceito útil como um passo na resolução de problemas complexos nos campos da Física e da Química. Neste caso específico, a teoria de matrizes aleatórias poderia possibilitar a compreensão do modo como a desordem num material não cristalino afeta as suas propriedades elétricas.

Geralmente, a determinação das características eletrónicas de materiais requer o cálculo de certas propriedades de matrizes, cujos elementos representam as energias dos eletrões e as suas interações, definidas a partir da forma como as moléculas se distribuem no material. A quantificação da influência de alterações físicas, como a alteração da temperatura ou a adição de impurezas, nas características dos materiais, requereria normalmente a variação de cada elemento matricial e a determinação da sua influência nas propriedades da matriz. No caso de materiais desordenados, os valores das próprias matrizes iniciais não são conhecidos com precisão, tornando o problema matemático muito difícil de resolver. Todavia Chen explica que "a teoria de matrizes aleatórias resolve este problema já que utiliza distribuições de probabilidade dispensando o cálculo dos valores precisos".

Assim, o novo método torna possível a translação de informação básica sobre o nível de desordem na estrutura molecular do material numa previsão das suas propriedades elétricas. Especificamente, o método desenvolvido transforma um problema matricial demasiado complexo para ser resolvido facilmente por métodos matemáticos tradicionais, num problema aproximado gerado pela combinação de duas matrizes cujas propriedades podem ser calculadas de uma forma simples.

De qualquer modo, os investigadores concluíram que o seu método aproximativo proporcionava resultados com uma elevada exatidão. Assim, a qualidade dos resultados obtidos levou a equipa a investigar as razões para a elevada exatidão do método que, por sua vez, conduziram a novas descobertas matemáticas no campo da teoria da probabilidade livre.

Chen afirma que "os resultados são um primeiro passo promissor na obtenção de soluções altamente exatas de modelos muito mais sofisticados e uma extensão destes métodos pode conduzir a uma redução do custo total da modelação computacional da nova geração de materiais e dispositivos solares".

Para além de Chen, a equipa inclui o professor associado de química Troy Van Voorhis do MIT, Eric Hontz e Matthew Welborn, o pós-doc Jeremy Moix, o professor de matemática Alan Edelman do MIT, Ramis Movassagh, e Alberto Suárez da Universidad Autónoma de Madrid.

(adaptado do artigo de 22/06/2012 de David Chandler: New technique allows simulation of noncrystalline materials, http://web.mit.edu/newsoffice/2012/simulating-solar-cells-0622.html)

Paulo Brito (paulo@ipb.pt) Instituto Politécnico de Bragança 